This item was submitted to Loughborough's Research Repository by the author.

Items in Figshare are protected by copyright, with all rights reserved, unless otherwise indicated.

\title{
Encapsulation techniques
}

PLEASE CITE THE PUBLISHED VERSION

http://www.springerreference.com/

PUBLISHER

(C) Springer

VERSION

AM (Accepted Manuscript)

LICENCE

CC BY-NC-ND 4.0

REPOSITORY RECORD

Vladisavljevic, Goran T.. 2012. "Encapsulation Techniques”. figshare. https://hdl.handle.net/2134/10606. 
This item was submitted to Loughborough's Institutional Repository (https://dspace.lboro.ac.uk/) by the author and is made available under the following Creative Commons Licence conditions.

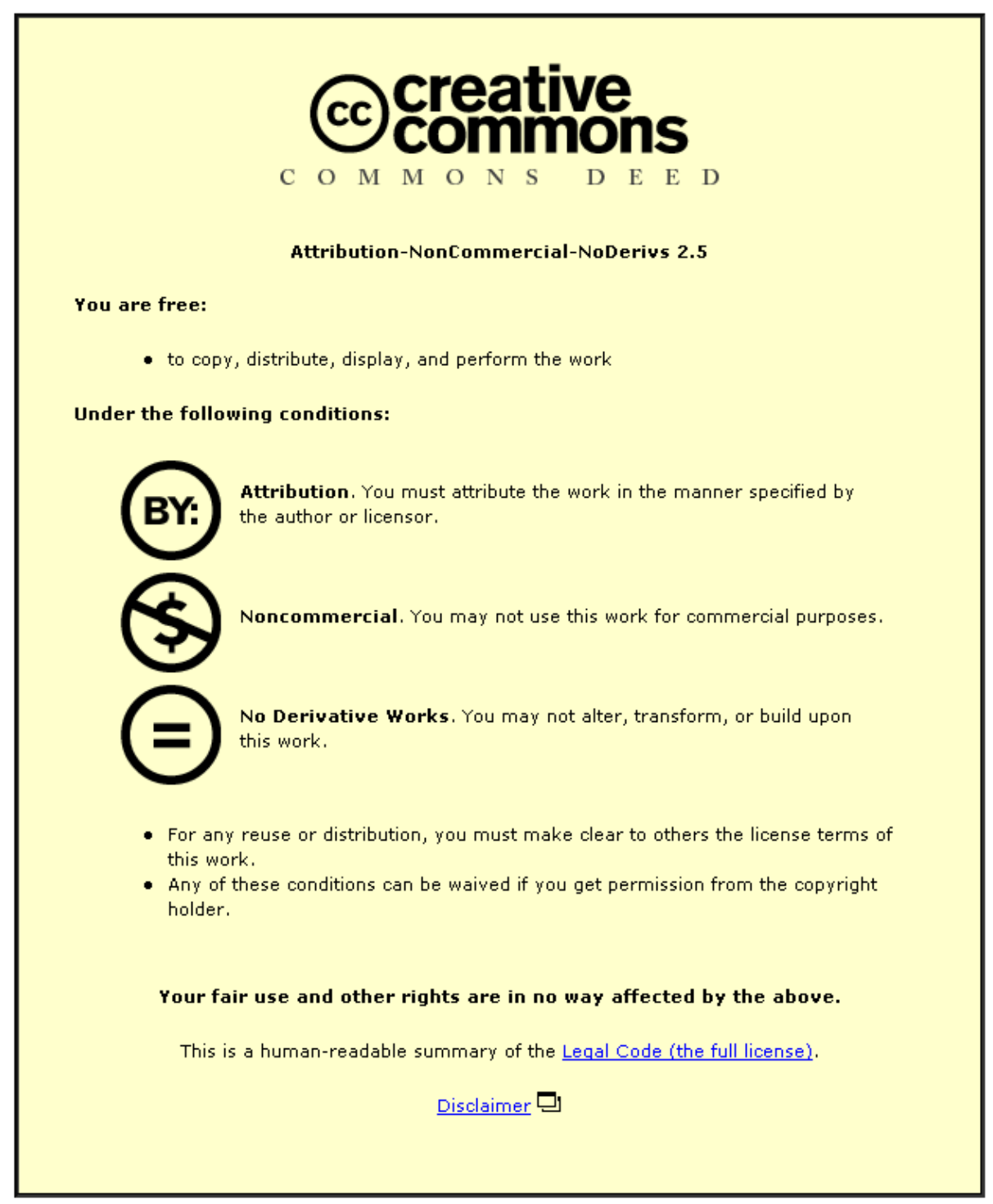

For the full text of this licence, please go to: http://creativecommons.org/licenses/by-nc-nd/2.5/ 


\section{Encapsulation techniques}

Goran T. Vladisavljević, Chemical Engineering Department, Loughborough University, Loughborough, Leicestershire, LE11 3TU, United Kingdom.

The encapsulation technique of choice depends on the type and physical properties of the core and shell material. The chosen encapsulation technique should give a high encapsulation efficiency and loading capacity of actives, capsules should not exhibit aggregation or adherence, capsules should have a narrow particle size distribution without tails, threads or dents on the surface and the process should be suitable for industrial scale production.

Depending of the initial physical state of the core material, two different fabrication routes can be distinguished: (i) Coating solid particles by shell forming material in a fluidized bed or pan coater; (ii) Dispersing a capsule forming material in the form of droplets in another immiscible liquid or air, followed by droplet solidification. There is a variety of atomization and dripping processes by which a liquid phase can be dispersed in the air environment (Table 1). An extrusion through nozzle can be assisted by vibrating the nozzle, providing a coaxial air or liquid flow or creating an electrostatic or centrifugal field to pull the droplets from the tip of a nozzle (Table 1).

Table 1. Classification of dispersion techniques used in encapsulation processes

\begin{tabular}{|l|l|}
\hline \multicolumn{1}{|c|}{ Liquid/air dispersion } & Liquid/liquid dispersion \\
\hline Atomization & Emulsification \\
-Pressure nozzle & -High pressure homogenizers \\
-Two fluid nozzle & -Ultrasound homogenizers \\
-Spinning disc & -Static mixers \\
Dripping/Jet break up & -Rotor/stator devices \\
-Simple dripping & -Microfluidic devices \\
-Electrostatic extrusion & -Membrane emulsification \\
-coaxial air/liquid flow & -Microchannel emulsification \\
-Jet cutting & -Inkjet printing \\
-Centrifugal nozzle & Micellization \\
-Vibrating nozzle & $\mathbf{p p}$ \\
\hline
\end{tabular}

Depending on the chemical composition of shell/matrix forming material, solidification of air suspended droplets can be achieved by solvent evaporation, cooling or crosslinking in a hardening bath. Emulsification routes involve emulsification of a solution or suspension of actives in a continuous phase liquid, followed by shell/matrix formation by internal gelation, 
polymerization, layer-by-layer electrostatic deposition, internal phase separation, coacervation, etc (Table 2).

Table 2. Common methods of solid shell/matrix formation in encapsulation processes

\begin{tabular}{|c|c|c|}
\hline Mechanical/Thermal & Physicochemical & Chemical \\
\hline $\begin{array}{l}\text { Cooling } \\
\text { Freezing } \\
\text { Pan coating } \\
\text { Fluidized-bed coating } \\
\text {-Top spray } \\
\text {-Bottom spray } \\
\text {-Tangential spray } \\
\text {-Wurster process }\end{array}$ & $\begin{array}{l}\text { Solvent removal } \\
\text {-Evaporation or drying } \\
\text {-Liquid extraction } \\
\text { Layer-by layer deposition } \\
\text { Self-assembly } \\
\text { Simple/complex coacervation } \\
\text { Ionotropic gelation } \\
\text { Internal phase separation }\end{array}$ & $\begin{array}{l}\text { Suspension polymerization } \\
\text {-One stage (direct) } \\
\text { suspension polymerization } \\
\text {-Two-stage suspension } \\
\text { polymerization (droplet } \\
\text { swelling method) } \\
\text { Interfacial polycondensation } \\
\text { Sol-gel chemistry }\end{array}$ \\
\hline
\end{tabular}

Hydrogel capsules contain a hydrophilic active entrapped within a hydrophilic polymer network that can absorb and hold large amount of water. A gel network can be formed by chemical gelation (polymerisation by free-radical processes or via condensation) or by physical gelation, which can involve heating (heat-setting gels), cooling (cold-setting gels) or the addition of multivalent counterions (ionotropic gelation). In the internal ionotropic gelation, the droplets of W/O emulsion contain a gel-forming polymer (e.g. alginate) and a crosslinking agent in a nondissociated form (e.g. $\mathrm{Ca}^{2+}$ in the form of $\mathrm{CaCO}_{3}$ ), whereas the continuous oil phase contains a species (e.g. $\mathrm{H}^{+}$) that diffuses into the droplets and triggers the release of crosslinking agent in its active form and subsequent gelation. In the external ionotropic gelation, the droplets containing only a gel-forming polymer solution fall into a hardening bath, where a crosslinking reaction occurs (Zhang et al. 2007).

Coacervation involves the phase separation of one or more polymers from the initial solution and the subsequent deposition of the newly formed coacervate phase around the active ingredient suspended or emulsified in the same reaction media. In simple coacervation, phase separation is achieved by addition of desolvating agent (alcohol or salt) or by change in temperature or $\mathrm{pH}$, whereas complex coacervation involves reaction between two oppositely charged polymers. The three basic steps in coacervation are: (i) Phase separation in a suspension or emulsion of active ingredient which leads to a three-phase system consisting of a polymer-rich liquid phase (coacervate phase), a polymer-lean liquid and a solid or liquid phase containing active ingredient; (ii) Deposition of the coacervate phase onto the dispersed particles or droplets; and (iii) Hardening of the coating (Zuidam and Shimoni 2010).

Solid lipid microparticles contain active ingredients entrapped within a high melting point lipid, such as fatty alcohols, fatty acids, fatty acid esters of glycerol, hydrogenated fatty acid esters, waxes, etc. Solid lipid microparticles are usually produced by a temperature-controlled emulsification of high melting point lipids followed by cooling or by solvent evaporation 
method. In the solvent evaporation method, a high melting point oil is dissolved in an organic solvent and the mixture is emulsified with an aqueous phase at room temperature. The solid particles are then formed by evaporation of the organic solvent. In this case, solid lipid particles are smaller than the initial oil droplets, whereas with a temperature-controlled emulsification, solid lipid microparticles are of the same size as the initial oil droplets. Watersoluble substances can be encapsulated by forming a W/O/W prior to solvent evaporation or cooling (Jaspart et al. 2005).

Liposomes are usually prepared using two approaches: (i) Hydration of dry lipid films with an aqueous solution resulting in formation of large multilamellar vesicles (MLV), which is then followed by size reduction of MLVs by sonication, microfluidization, repetitive freezing and thawing or extrusion through track-etch polycarbonate membranes; (ii) Mixing a nonaqueous lipid solution with an aqueous solution (Walde and Ichikawa 2001).

\section{References:}

Jaspart S, Piel G, Delattre L, Evrard B (2005) Solid lipid microparticles: formulation, preparation, characterisation, drug release and applications. Expert Opin Drug Deliv 2:1-13.

Walde P, Ichikawa S (2001) Enzymes inside lipid vesicles: preparation, reactivity and applications. Biomol Eng 18:143-177.

Zhang H, Tumarkin E, Sullan RMA, Walker GC, Kumacheva E (2007) Exploring microfluidic routes to microgels of biological polymers. Macromol Rapid Commun 28:527538.

Zuidam NJ, Shimoni E (2010) Overview of microencapsulates for use in food products or processes and methods to make them. In: Zuidam NJ, Nedović VA (Eds) Encapsulation technologies for active food ingredients and food processing, Springer, New York, pp 3-29. 